\title{
UM FANTASMAGÓRICO TRIÂNGULO AMOROSO: PRESENÇA DE ANITA
}

\section{Maria Luiza Guarnieri Atik}

Resumo: A crença de que os mortos ou seus fantasmas retornam ao mundo dos vivos está presente no imaginário de inúmeras culturas. O retorno dos mortos é também um tema recorrente na literatura. Como assinala Remo Ceserani (2006, p. 80), podemos pensar nas "visitas de além-mundo de grandes personagens" presentes nas obras de Virgilio e de Dante, ou ainda "nas bruxas e nos espíritos dos dramas shakespearianos". O objetivo do nosso trabalho é observar como se manifestam as projeções fantasmáticas em algumas cenas do telefilme Presença de Anita e examinar como, no processo de transposição do romance de Mário Donato para a mídia visual, se reconfiguram os fantasmas interiores do protagonista, num clima tenso de erotismo, sensualidade, paixão, ciúmes e morte.

Palavras-chave: Literatura brasileira. Telefilme. Transposição.

"E m sua obra O Fantástico, Remo Ceserani (2006) apresenta alguns temas ou núcleos temáticos mais difundidos e praticados na literatura fantástica; dentre eles destacamos o da "vida dos mortos". A crença de os mortos ou de seus fantasmas retornarem ao mundo dos vivos está presente no imaginário de inúmeras culturas. Vida e morte são conceitos que aparecem indissociáveis na mentalidade de muitos povos antigos, distanciando-se, de certa forma, da maneira como ambos são compreendidos e interpretados pelo homem atual.

Na Idade Média, por exemplo, o medo que se tinha dos fantasmas estava muito mais relacionado à questão da morte. Para o homem medieval, a morte não era um conceito abstrato, ela estava presente concretamente em seu dia a dia e não significava propriamente um fim, mas um momento de busca, de passagem. No ritual de passagem, para que o morto tivesse êxito, era preciso estar preparado, pois caso contrário não conseguiria transpor os horrores da travessia. Assim, o aparecimento do fantasma de um morto estava associado ao fato 
de ele não ter conseguido o repouso eterno, à questão de ele ter sido amaldiçoado, ou ainda, à perspectiva de que tenha voltado para trazer más notícias do além-túmulo.

O retorno dos mortos não é um tema novo na literatura. Como assinala Ceserani (2006, p. 80), podemos pensar no Diálogo dos mortos, de Luciano de Samósata (125-190 d.C.), nas "visitas de além-mundo de grandes personagens" presentes nas obras de Virgílio e de Dante, ou ainda "nas bruxas e nos espíritos dos dramas shakespearianos".

No século XIX, a literatura foi invadida por fantasmas, mortos-vivos, vampiros e lobisomens, que, com suas nuances de incerteza e dubiedade, se tornaram a força motriz de inúmeras narrativas. Já na literatura fantástica do século XX, o padrão literário da figuração fantasmagórica constrói-se a partir de novos aspectos. As figuras monstruosas reconfiguram-se; monstros e fantasmas deixam de ser exterior ao homem e passam a habitar a interioridade dos sujeitos. $\mathrm{O}$ homem e suas angústias existenciais tornam-se em si mesmo a imagem do insólito e, a isso, se une um inevitável efeito de inquietude ante a sua incapacidade de discernir o possivel do impossivel, o real do imaginário. Surge, como nos aponta Ceserani (2006, p. 80), a temática do imaginário, "que é feita de projeções fantasmáticas, sublimações extremas (glorificações, enaltecimentos), espiritualizações do eros".

O objetivo do nosso trabalho é examinar como se manifestam as projeções fantasmáticas em algumas cenas do telefilme Presença de Anita, exibido pela TV Globo em janeiro de 2015, na programação dos eventos do seu Projeto Luz, Câmera, 50 Anos. O telefilme é, na verdade, uma versão condensada da minissérie Presença de Anita, de autoria de Manoel Carlos, exibida na Rede Globo em 2001. A minissérie, composta por 16 capítulos, foi livremente inspirada no romance homônimo de Mário Donato, publicado em 1948.

O romance de Donato pode ser considerado um dos mais ousados da literatura brasileira, na década de 1940. Tal característica colocou-o em evidência no ano de seu lançamento, principalmente por seu erotismo que ia de encontro aos valores morais impostos pela sociedade da época. Mário Donato vivenciou dias de fama, mas também de muitas controvérsias, chegando a provocar a ira da Igreja, que ameaçou excomungá-lo. Donato investiga com profundidade toda a subjetividade das personagens, dando ênfase à sensualidade, à paixão e, principalmente, à tragédia pessoal do ser humano. Crime, mistério, culpa e prazeres fundem-se na narrativa de forma que se construa uma trama inovadora, cativante e enigmática.

O narrador da trama romanesca, por sua vez, torna-nos quase cúmplices do protagonista, Eduardo, e de sua obsessiva busca pelo amor idealizado, projetado na figura de Cíntia - mulher criada por sua imaginação, a qual ganha forma em seus desenhos:

[...] brincando sobre o papel quadriculado que a prancha mantinha estendido, ele traçara um dorso de mulher, um " $\mathrm{S}$ " suavemente esguio, as hastes morrendo no esfumaçamento de grafite, quase como uma clava de sol que se desenrola e canta em surdina. Uma cabeleira nasceu ali, desnastrando-se volutuosamente em longas ondas disciplinadas que se espraiavam nas têmporas imaginárias. "Quase loura", pensou Eduardo.

[...] 
Debuxou-lhe o pescoço - a forma clássica duma taça de champanha, e logo brotaram por si mesmos os seios da figura, minúsculos e atrevidos no corte do perfil, e sob eles, impassível e monótono, adelgaçou-se o ventre, retraindo-se até a raiz das coxas. $E$ os traços escorreram livremente para baixo, interrompendo-se nos joelhos apertados como com medo, guardando um tesouro (DONATO, 2001, p. 23).

Eduardo procura em cada mulher com quem se envolve traços e características daquela que é a sua razão de viver, mas se depara o tempo todo com "quase Cíntias". No fundo, Eduardo tenta, por meio desses encontros amorosos, superar suas angústias relacionadas ao casamento sofrivel, infeliz e medíocre com Lúcia.

Sua esposa e as mulheres à sua volta (cunhadas) são figuras que atormentam sua realidade cotidiana e estimulam os seus devaneios. Essa presença feminina é o pior dos fantasmas, os quais assombram a sua vida miserável, fazendo-o sofrer ainda mais com sua fragilidade e fraqueza.

Em sua busca pela mulher idealizada, o protagonista deixa-se seduzir por Anita, uma ninfeta de 17 anos, linda, sensual e perturbadora, mas com um passado obscuro e que, aparentemente, está sozinha no mundo. Num clima de erotismo, paixão e ciúmes, o casal vive um tórrido romance, que coloca em xeque os valores sociais e morais e acaba abalando a sociedade local: Florença, uma pequena cidade do interior de São Paulo.

Apesar de todos os obstáculos, Anita acreditava que seus sonhos poderiam ser realizados, e o fato de Eduardo ter uma esposa e filhos faz com que ela sinta mais prazer em criar um jogo de sedução que estimula sua autoconfiança e gera uma busca desenfreada por viver uma paixão proibida. Anita leva esse relacionamento amoroso ao extremo, propondo um pacto de morte. Eduardo mata Anita e, em seguida, tenta se suicidar, mas acaba apenas se ferindo na testa.

A hipótese de um duplo suicídio gera um novo direcionamento à trama romanesca. A família, principalmente a esposa, tenta livrá-lo da prisão, e o advogado o convence, ainda no hospital, de que Anita se matara. O laudo da Polícia Técnica comprovara que o tiro fora à queima-roupa e "ligeiramente desviado da direita para esquerda e de baixo para cima" (DONATO, 2001, p. 88). Eduardo tenta revelar ao advogado a verdade, que "fora ele que atirara em Anita, deliberadamente" e que "ele sugerira o suicídio, embora não tivesse o desejo real de suicidar-se" (DONATO, 2001, p. 88). Embora absolvido pelo júri, a tensão entre realidade e imaginação, entre realidade e delírio, propicia o surgimento do fantasma de Anita e, consequentemente, um pavor diante da possibilidade de sua própria morte. O maior desejo de Eduardo é viver. Viver intensamente, em busca da mulher ideal, a "Cintia" de seus desenhos. Assim, depois da morte de Anita, Eduardo parte em busca de uma nova aventura amorosa. E se, num primeiro momento, ele escolhe duas mulheres com quem se relacionar - Lúcia (a esposa) e Anita (a amante) - é somente com Diana, sua cunhada, que decide viver para sempre.

O telefilme reconfigura os fantasmas interiores do protagonista, agora denominado Fernando, e num clima tenso de erotismo, sensualidade, paixão, ciúmes e tragédia pessoal coloca em cena o embate entre família e paixão carnal, vida e morte, sagrado e profano. 
Na trama filmica, o erotismo e a sensualidade de Anita são explorados de forma intensa, por atitudes, falas e trajes íntimos. Seu corpo desnudo aparece em diferentes planos e ângulos na tela, demonstrando uma total descontração diante do amado e constrangendo-o, muitas vezes, quando sem qualquer pudor vai até a sacada do quarto, seminua. O erotismo e a sensualidade de Anita são explorados não apenas no relacionamento amoroso dos amantes, mas também pelo olhar de intenso desejo do jovem Zezinho, que, como um voyeur, espia de uma pequena janela do armazém em que trabalha os momentos íntimos do casal. Configura-se, pouco a pouco, um triângulo amoroso. Anita insinua-se para Zezinho, até que em determinado momento acaba por iniciá-lo sexualmente. Por outro lado, o medo de perder Fernando para a esposa faz com que Anita lhe revele não só o seu relacionamento com Zezinho, mas também o modo como iniciara a sua vida sexual com um pintor idoso, quando ainda era apenas uma menina. Jogando perigosamente com o ciúme do amante, Anita tenta manter a posse do objeto amado.

Em sua obra O erotismo, Georges Bataille (1987) defende que o erotismo é uma experiência unicamente humana, que não existe no reino animal. Segundo Bataille (1987), somos seres descontínuos, pois há, entre cada ser, um abismo que os separa. E entre as formas de busca da continuidade estão o erotismo, a morte, a reprodução e a violência, elementos intimamente vinculados à existência humana.

Para Bataille (1987), existem três formas de erotismo: o erotismo dos corpos, o do coração e o do sagrado, todos relacionados à substituição do isolamento do ser pela busca da continuidade perene. O erotismo dos corações é o erotismo dos amantes, o qual é perpassado pela paixão, por um sentimento arrebatador. A própria paixão, contudo, traz uma desordem tão violenta que o prazer pode se transformar em sofrimento e, consequentemente, em violência e morte.

Se o amante não pode possuir o ser amado, algumas vezes pensa em matá-lo: muitas vezes ele preferiria matar a perdê-lo. Ele deseja em outros casos sua própria morte. O que está em jogo nessa fúria é o sentimento de uma continuidade possível percebida no ser amado. Ao amante parece que só o ser amado [...] pode neste mundo realizar o que nossos limites não permitem a plena fusão de dois seres, a continuidade de dois seres descontínuos (BATAILLE, 1987, p. 15).

$\mathrm{Na}$ busca pela completude emergem duas forças opostas: vida e morte. Anita, recriada por Manoel Carlos, com seu jeito visceral de ser, de falar sobre o amor, sobre a vida, encanta Fernando e ambos vivem essa paixão desenfreada. Ao longo do telefilme, Anita pronuncia, inúmeras vezes, duas frases: "Existe alguma coisa mais parecida com o amor do que a morte?" e "Nada é coincidência, tudo está escrito". Para Anita, o desejo de união encontra na morte a possibilidade de fusão, de eterna completude. É com esse desejo que propõe o pacto de morrerem juntos. Em seus momentos derradeiros, Anita pede a Fernando que cumpra o pacto de morte. Para ela, a morte significa união, amor, completude do ser, como os andróginos, buscando a outra metade. Anita morre por e de amor, de desejo, e essa morte não é aceita pela sociedade.

A singularidade do comportamento de Anita está no fato de não se submeter jamais aos paradigmas morais impostos pela sociedade, colocando-se a serviço de suas volúpias e de seus desejos. Anita representa a transgressão do começo ao fim da narrativa filmica. 
Por outro lado, ao condensar as cenas mais dramáticas da minissérie, constata-se que, na trama do telefilme, é colocado em primeiro plano o drama pessoal de Fernando: o embate entre família e paixão carnal. Ao descobrir que Anita enviou uma carta à sua esposa, contando-lhe que estava grávida, como também ocorre no romance, a narrativa filmica chega ao seu climax. Anita, num primeiro momento, diz a Fernando que o filho que espera pode ser de Zezinho e logo depois afirma que não está grávida, rindo de forma debochada e irônica. Aos olhos de Fernando, tudo não passa de uma grande chantagem. Novamente, Anita se arrisca em um jogo perigoso para manter a posse do objeto amado, mas acaba sendo assassinada pelo amante, com uma faca enterrada no ventre.

A cena do assassinato é presenciada por Zezinho da pequena janela do armazém. Descontrolado, entra na casa de Anita e, em sua luta com Fernando, tenta matá-lo com a mesma faca. Há, contudo, uma inversão de papéis: no momento em que os vizinhos entram no quarto, Zezinho foge pela varanda da casa, empunhando a faca. De defensor da amada, torna-se assassino. Fernando, por sua vez, passa de assassino a vitima perante os olhos das testemunhas.

No romance, também o protagonista Eduardo de assassino passa a vítima, mas por intermédio de um discurso muito bem arquitetado pelo advogado da família:

[...] Precisamos evitar contradições. Haja o que houver, o senhor não teve nem nunca poderia ter tido a ideia de suicídio. O senhor ligara-se à vítima, mas com certeza de que tal ligação não poderia mesmo ser permanente. E estava prestes a separar-se dela, dado o inconveniente das suas atitudes que o comprometiam. Quem teve a ideia foi ela, com seu temperamento veemente, como se depreende pela carta enviada à dona Lúcia. É fácil provar que a vítima estava à margem da sociedade e que lançava de recursos escusos. E o senhor relutou, embora, num momento de depressão, criado pela remessa da carta, concordasse em morrer com ela. Não é assim?

- e, sem esperar resposta: - De forma que a senhora, diante de sua hesitação [...] atirou-se. Compreendeu? E o senhor deprimido, fora de si, temeroso das consequências daquela loucura aos olhos de sua família e da sociedade, tentou matar-se (DONATO, 2001, p. 90).

Como destacamos no início do nosso trabalho, no século XX, os fantasmas deixam de ser exterior ao homem e passam a habitar a interioridade dos sujeitos. Vale a pena recordar a definição de Pierre-Georges Castex (apud CESERANI, 2006, p. 46) sobre o fantástico:

O fantástico não se confunde com as histórias de invenção convencionais, como as narrações mitológicas ou os contos de fadas, que implicam uma transferência da nossa mente (un dépaysement de l'esprit) para outro mundo. O fantástico, ao contrário, é caracterizado por uma invasão repentina do mistério no quadro da vida real; está ligado, em geral, aos estados mórbidos da consciência, a qual, fenômenos como aqueles dos pesadelos ou do delírio, projetam diante de si as imagens das suas angústias e dos seus horrores.

A versão televisual explora as angustiantes questões existenciais de forma direta. No caso de Anita, explora o prazer na infância e seus desdobramentos no início da fase adulta. Em relação a Fernando, traz à tona suas interdições mais intimas, tentando assumir que, mesmo casado, ainda não encontrou a mulher 
idealizada. Anita parecia ser, num primeiro momento, a concretização do erotismo da figura feminina que ele desenhava, há tanto tempo, em uma folha de papel. O papel, espaço criativo, metamorfoseia-se em lugar de transgressão, ou melhor, lugar onde ele exerce um contínuo exercício de voyeurismo, o qual the permite sublimar todas as suas limitações.

São os fantasmas interiores, entretanto, que assolam os pensamentos de Fernando e são colocados em foco nas cenas finais do telefilme. A consciência da culpa no assassinato de Anita, a sobrevivência de Zezinho em estado crítico na UTI do hospital, a hostilidade ou a ironia de alguns membros da família em relação ao seu caso amoroso e a perda do afeto da esposa constituem um conjunto de fatos que o desestabilizam emocionalmente, levando-o a um estado de angústia e depressão, seguido por delírios e alucinações.

Delírios e alucinações que permitem explorar as manifestações do insólito na narrativa audiovisual, tornando-se palpável o espectro de Anita. Na porta do hospital, manifesta-se a primeira projeção do fantasma de Anita aos olhos do amante. Fernando tem a sensação de ouvir a risada irônica de Anita. Desesperado, olha à sua volta, até que se depara com a sua imagem em uma das janelas do hospital. Vai até o quarto e encontra-o vazio. A certeza da presença de Anita no quarto é desconstruída pelas palavras da enfermeira, que lhe informa que a família já retirou o corpo da morta. Fernando entra em estado de pânico e tem uma vertigem. É novamente hospitalizado.

Aos olhos do espectador, os delírios do protagonista ganham tal intensidade e são tão reais, que as manifestações de fatos insólitos deixam de ser questionadas. Em um de seus delírios, Fernando presencia Anita acariciando e beijando Zezinho na UTI. À medida que o moribundo ganha vida, a relação amorosa se intensifica. Fernando bate com violência no vidro da sala da UTI e grita descontroladamente. Entretanto, tudo não passa de uma grande alucinação.

A projeção do espectro de Anita ganha maior relevo nas cenas finais da narrativa audiovisual, quando Fernando retorna à casa de Anita e descobre pela sua mãe que ela estava realmente grávida, conforme atesta a autópsia. Sozinho na casa, Fernando senta-se na cama e começa a desenhar a "mulher idealizada". As luzes se apagam misteriosamente, e a risada de Anita ecoa pelo ambiente. Fernando grita para que ela apareça.

A música "Ne me quitte pas" ("Não me abandone") e a transformação progressiva da iluminação do cenário, para sugerir a passagem a um outro plano de realidade, são alguns dos recursos audiovisuais utilizados para nos aproximar do delírio final de Fernando. O plano alucinatório é entrecortado pela inserção de uma cena natalina em família. Tais recursos permitem que o profano e o sagrado se entrecruzem.

Assim, enquanto na casa da família de Fernando todos estão felizes, vivenciando o espírito natalino e cantando em coro "Noite Feliz", no sobrado, agora iluminado por luz de velas, há um embate entre o fantasma de Anita e Fernando.

Nas cenas finais da adaptação audiovisual, a imagem fantasmagórica de Anita ganha concretude, é um fenômeno sonoro, tanto quanto visual e tátil. Ela ataca Fernando verbalmente, chamando-o de covarde por não assumir a sua culpa, por não revelar a verdade à sua esposa, ao mesmo tempo em que tenta convencê-lo a ficar com ela para sempre, amando-a pela última vez. Fernando, devido ao seu estado físico e psíquico anormal, grita que não quer 
morrer, que está vivo, que tem o direito de ser feliz; busca convencer a si mesmo que está apenas imaginando tudo isso. Tenta, na verdade, afastar de seu pensamento o seu medo mais velado: o da morte.

Ao adotar o ponto de vista da personagem, a trama audiovisual nos permite ver na tela o que se supõe que Fernando perceba e sinta em seu delírio. Ao materializar-se o conteúdo mental da personagem, o insólito instaura-se na narrativa e é explorado até as últimas consequências. Fernando tenta se desvencilhar dos braços de Anita, mas acaba sendo dominado e entrega-se. As cortinas do quarto começam a pegar fogo e, em alguns minutos, todo o ambiente é envolvido pelas chamas. O deleite do ato sexual realiza-se em meio às labaredas e, em segundo plano, os corpos parecem estar amalgamados. Por fim, tem-se a grande explosão do sobrado.

Levando-se em conta os dois niveis de realidade, a família comemorando o Natal e a morte dos amantes em meio às labaredas, a adaptação do romance de Mário Donato ganha uma nova configuração, muito mais próxima do universo do fantástico, pois um dos recursos tradicionais da narrativa fantástica é a presença da figura do fantasma, do ser que retorna da morte e se instala no mundo dos vivos, introduzindo uma transgressão nos códigos de funcionamento do real. Essa dimensão transgressora é o que determina o valor da narrativa fantástica. No caso da adaptação audiovisual, a "presença do fantasma de Anita", inadmissível dentro do mundo real, torna-se aceitável aos olhos do espectador enquanto materialização de uma intensa desordem interior do protagonista, sobretudo emocional, capaz de tornar real o próprio delírio.

\section{A ghostly love triangle: Presença de Anita}

Abstract: The belief of the dead or the idea of their ghosts returning to the living world is in the minds of different cultures. The return of the dead is also a recurring theme in literature. As Remo Ceserani (2006) noted, we can think in the "great character visits from beyond the world" in the works of Virgil and Dante, or "the witches and spirits of Shakespearean dramas". The purpose of this study is, firstly, to examine how phantasmagorical projections are exposed in some scenes of the telefilm Presença de Anita; secondly, we observe how Mario Donato's novel transposition process for visual media reshape the inner ghosts of the protagonist under a tense erotic climate of sensuality, passion, jealousy and death.

Keywords: Brazilian literature. Telefilm. Transposition. 


\section{REFERÊNCIAS}

BATAILlE, G. O erotismo. Porto Alegre: L\&PM, 1987.

CESERANI, R. O fantástico. Curitiba: Editora UFPR, 2006.

DONATO, M. Presença de Anita. Rio de Janeiro: Objetiva, 2001.

Recebido em agosto de 2016. Aprovado em novembro de 2016. 